\begin{tabular}{|lllll}
\hline Motrivivência & Ano XX, & No 31, P. & $79-98$ & Dez./2008
\end{tabular}

\title{
As Danças Folclóricas e Populares no Currículo da Educação Física: possibilidades e desafios
}

\author{
Silvia Pavesi Sborquia?' \\ Marcos Garcia Neira ${ }^{2}$
}

\begin{abstract}
Resumo
Inspirado nas teorias pós-críticas da educação, o currículo da Educação

Física tenciona posicionar os educandos como sujeitos no alcance de uma sociedade mais justa e menos desigual. Ao conceber o currículo como campo político em que se constroem as identidades dos indivíduos, é fundamental que a variedade do patrimônio cultural corporal dos grupos que coabitam a sociedade seja problematizada no ambiente escolar. Desconstruindo

o privilégio destinado às danças da cultura midiática na escola, o presente artigo defende a vivência e o estudo das danças folclóricas e
\end{abstract}

1 Professora do Departamento de Educação Física da Universidade Estadual de Ponta Grossa. Contato: silviapavesi@bol.com.br

2 Professor Doutor na Faculdade de Educação da Universidade de São Paulo. 
populares. Para tanto, fundamentase nos Estudos Culturais e sugere encaminhamentos para a prática pedagógica.

Palavras-chave: Currículo; Cultura; Dança; Educação Física. ral Studies are used as a reference and suggests ways for pedagogical practice.

Key words: Curriculum; Culture; Dance; Physical Education

\section{Introdução}

O debate sobre a dança como um tema a ser tratado pela educação física na escola é muito recente. Os questionamentos sobre quais danças devem ser abordadas no currículo escolar e como desenvolver um trabalho pedagógico com este conhecimento tem sido foco de indagações no âmbito acadêmico (BRASILEIRO, 2001; SALES, 2003).

Algumas propostas foram elaboradas objetivando elucidar tal problemática (SBORQUIA, 2002; EHRENBERG, 2008), no entanto ao pesquisar como a dança é tratada nas abordagens metodológicas da educação física (LARA et. al., 2007) aponta que a maioria dos proponentes concordam com o fato de que, atualmente, a dança não está presente na escola e de que não existe uma fundamentação teórica para o encaminhamento desse conhecimento nas aulas de educação física. Tal fato revela a carência de conhecimentos elucidativos sobre o trato e a sistematização da dança na escola, bem como o incentivo à

divulgação das produções teóricas voltadas para o tema.

Ao confrontar os problemas reais da prática educativa com as preposições teóricas da educação e da educação física, Sborquia (2008) considera que as mudanças no mundo da escola serão realizadas pelos próprios professores. É necessário romper com o paradigma da racionalidade técnica no qual o professor limita-se à execução de tarefas planejadas pelos setores acadêmicos ou administrativos, para um paradigma em que os professores da escola, em consonância com a comunidade, assumam a autoria do currículo, dimensionando os temas abordados e os conteúdos ensinados a partir de uma leitura da realidade social, bem como promovam a avaliação sistemática da aprendizagem dos alunos como forma de reorientar suas ações didáticas. Isto quer dizer que a prática deverá ser compreendida $\mathrm{e}$ contextualizada pela teoria em um constante movimento dialético.

Estudos anteriores observaram que a dança na escola se 
resume a movimentos de repertório, com finalidade em si mesma (SBORQUIA, 2002; BRASILEIRO, 2006). Mesmo quando o professor tenta romper com as "dancinhas" de datas comemorativas para abordar as danças folclóricas, por exemplo, o processo educativo praticamente se isenta de qualquer reflexão mais profunda. Comumente, o que se vê é a aproximação dos alunos mediante a exposição pelo professor, o ensaio e apresentação. Enfim, seja qual for a dança, o fazer pedagógico tem sido o mesmo.

\section{A dança como manifestação cultural}

Partindo de uma compreensão da Educação Física como componente curricular que trata pedagogicamente da cultura corporal (SOARES et. al., 1992) e considerando a inserção da dança no currículo mediante uma perspectiva pós-crítica (NEIRA e NUNES, 2009), compreende-se a dança como manifestação da expressividade humana produzida e reproduzida conforme o contexto, crenças, valores e características de cada grupo social (SBORQUIA e PÉREZ GALLARDO, 2006). A argumentação desenvolvida pelos autores permite considerar a dança como artefato cultural produzido pela gestualidade sis- tematizada, passível, portanto, de tematização no interior do currículo da Educação Física.

A concepção de cultura que atravessa a presente discussão toma como base a discussão travada no âmbito dos Estudos Culturais. Nelson, Treichler e Grossberg (1995) definem os Estudos Culturais como um termo de conveniência para uma gama bastante dispersa de posições teóricas e políticas. Sendo profundamente antidisciplinares, sinteticamente, pode-se dizer que partilham o compromisso de examinar práticas culturais do ponto de vista de seu envolvimento com, e no interior de relações de poder.

Cultura se refere à dimensão simbólica presente nos significados compartilhados por um determinado grupo. Cultura é aqui concebida como prática social, não como coisa ou estado de ser. Nesse enfoque, coisas e eventos do mundo natural existem, mas não apresentam sentidos intrínsecos: os significados são atribuídos a partir da linguagem. "Quando um grupo compartilha uma cultura, compartilha um conjunto de significados construídos, ensinados e aprendidos nas práticas de utilização da linguagem" (MOREIRA e CANDAU, 2007, p. 27).

A discussão atual em torno da cultura nos mostra que a expansão cultural atual é sem precedentes 
na História. A cultura, no século XX, assumiu uma função primordial na história quanto à sua estrutura e à organização das sociedades, pois, em função de novas tecnologias e da consequente revolução das informações, ocorre maior produção, circulação e trocas culturais. Mais ainda, a indústria cultural ocupa espaço central como elemento mediador em vários momentos políticos, econômicos e sociais. O que isso sugere é que o cotidiano está sendo alterado constantemente e esse não detém autonomia, pois sua constituição depende da sua relação com o global. Vivemos em uma época em que os riscos de homogeneização cultural, fruto da expansão constante da lógica capitalista, são permanentes, porém não tão simples como possa parecer, afinal toda relação social implica força e luta.

No campo teórico e político dos Estudos Culturais a cultura é entendida como espaço de luta, ou seja, qualquer transmissão cultural é sempre travada, disputada, conquistada e transformada pelos grupos envolvidos; uma construção que ocorre nas relações entre os diversos grupos sociais e entre seus membros (HALL, 2003).

Atuar como professor de Educação Física na escola ou como profissional de Educação Física nas demais instituições sociais requer um posicionamento teórico sobre o conceito de cultura e a análise de suas implicações na constituição da vida social. A análise cultural parte da concepção de que o mundo cultural e social torna-se, na interação social, naturalizado: sua origem social é esquecida (HALL, 1997). A tarefa da análise cultural consiste em desconstruir, em expor esse processo de naturalização.

É o caso, por exemplo, das danças da mídia quando produzidas unicamente para atender às demandas de mercado, acabam reproduzidas de forma acrítica no contexto educativo. Sborquia e Pérez Gallardo (2002) vão destacar a necessidade de análise e reflexão não só sobre sua transposição direta como também dos seus significados. Nas aulas de Educação Física não basta dançar, é necessário tematizar a dança em questão.

Inspirado nos Estudos Culturais, o currículo da Educação Física traz para o interior da escola uma variada gama de manifestações corporais, às quais serão submetidas a um permanente processo de tematização. Seguindo o raciocínio de Corazza (2003), tematizar significa abordar algumas das infinitas possibilidades que podem emergir a partir das leituras e interpretações da prática social de uma dada manifestação. No trabalho de Freire (1980), tematizar implica 
em procurar o maior compromisso possível do objeto de estudo numa realidade de fato, social, cultural e política. O que se pretende com a tematização é uma compreensão profunda da realidade em foco, desenvolvimento da capacidade crítica dos alunos enquanto sujeitos de conhecimento, desafiados pelo objeto a ser conhecido.

No decorrer das ações didáticas, é fundamental que o professor de Educação Física acompanhe e ajude os alunos a identificar quais significados sobre a dança estão sendo produzidos nos diversos segmentos da sociedade, quais os efeitos que as diversas manifestações da dança produzem sobre seus integrantes e como se constroem as relações históricas e de poder nesses grupos sociais, sem desprestigiar nem desqualificar qualquer dança, muito menos seus representantes. Ocorre que diante da força avassaladora da cultura midiática, as danças por ela e para ela produzidas invadem quase todos os ambientes disponíveis deixando pouco espaço para as demais manifestações rítmicas. Obviamente, tudo isso reflete nas representações que docentes e discentes elaboram acerca de qual dança deve ser tematizada na escola. O fato é que, geralmente, as danças populares e folclóricas são deixadas de lado e as midiáticas recebem toda a atenção, reprodu- zindo indefinidamente o ciclo de exaltação de determinados grupos em detrimento de outros.

\section{Folclore e Cultura popular}

O estudo sobre a cultura popular ou suas transformações deverá incidir sobre as mudanças no equilíbrio e nas relações das forças sociais em torno da cultura dos trabalhadores e dos pobres, nas tradições e formas de vida das classes populares (HALL, 2003). No debate cultural, o popular é entendido como categoria de oposição àquilo que é erudito, o que pertence às elites. Na tradição segregacionista da sociedade capitalista, o que é domínio do povo não pode ser um conteúdo das classes dominantes, como também não pode adentrar as fronteiras dos currículos escolares (TORRES SANTOMÉ, 1998).

A primeira distinção que se faz necessária no trato com o conhecimento da dança é o entendimento das relações estabelecidas entre folclore, cultura popular e as mudanças sociais. Pois, de tempos em tempos, certas produções populares têm sua categorização cultural modificada, saindo dos meios populares e invadindo setores mais restritos ou vice-versa.

Exemplificando essas relações, Sborquia e Pérez Gallardo (2006) abordam os vários significa- 
dos dados à dança, todos construídos diacronicamente em conjunto com as diversas transformações sociais. No início, seu sentido era mítico, sagrado. Seu uso estava atrelado às oferendas e graças necessárias à sobrevivência do grupo. $\mathrm{Na}$ Idade Média, sempre que as proibições se mostravam ineficazes, as manifestações da dança representavam a unificação entre o social, a realidade e a fuga das mazelas da vida cotidiana.

Na modernidade a dança foi codificada com base na racionalidade científica. $\mathrm{O}$ pensamento mecanicista dominado pela concepção de homem-máquina levou à sistematização do balé clássico e ao seu academicismo. A dança se tornou mecanizada nas sociedades ocidentais por todo esse período. O ser humano não podia expressar seus sentimentos e pensamentos, simplesmente reproduzia os movimentos padronizados. O balé clássico tornou-se o referencial erudito e prevaleceu hegemonicamente nos mais diversos grupos sociais. Alheias ao que acontecia nas elites, nos meios populares as danças eram outras, cujos movimentos, em certa medida, eram ressignificados e codificados pela dança clássica.

Lentamente, ao longo do século XIX e início do século XX, todos os dogmas foram postos em questão, nas artes, nas ciências, nas sociedades e nas religiões. Depois da ruptura causada pelas duas grandes Guerras Mundiais, a humanidade passou a utilizar uma nova linguagem para expressar as necessidades e sentimentos do século XX. A dança moderna surgiu mediante a contestação e rejeição do rigor acadêmico e dos artifícios do balé clássico. Procurou-se uma nova relação da dança com a vida real, tendo como inspiração a própria natureza e liberdade de expressão, como decorrência da conscientização de que era necessário extrapolar a cópia e a mímica. A dança moderna aprimorou métodos que permitiram a expressão corporal de sentimentos, ideias e outras experiências de vida, numa época nova e perturbadora da história. Inversamente ao pressuposto clássico, a dança moderna caracterizou-se por referenciar os movimentos nos próprios sujeitos.

Em meados do século XX, surge a dança contemporânea. Baseada numa mistura de linguagens artísticas, de interpretação e ressignificação das mais variadas manifestações da dança. A criação coreográfica caracteriza-se por um processo de hibridização cultural. Todavia, é importante que se diga que tanto a dança clássica, como a moderna e a contemporânea têm suas origens na cultura erudita, a partir da ressignificação dos elementos da cultura popular. 
Processos de transformação semelhantes são bastante comuns em diversos artefatos culturais ou, até mesmo, nos significados atribuídos a alguns dos conceitos aqui empregados. A origem do conceito de cultura popular, por exemplo, surgiu atrelada ao conceito de folclore. No decorrer do tempo, tanto um como o outro, foram depurados. Daí, não ser raro encontrá-los ora como sinônimos, ora radicalmente separados. O que torna necessário estabelecer alguns esclarecimentos acerca do sentido que atribuímos ao folclore e à cultura popular, com vistas a subsidiar a sua apropriação pelo currículo da Educação Física.

Festeja-se o dia Internacional do Folclore em 22 de agosto, porque nessa data, no ano de 1846, pela primeira vez a palavra Folk-Lore foi publicada na revista Londrina "The Atheneum", pelo arqueólogo inglês William John Thoms, propondo que se estudasse sistematicamente e preservasse tudo aquilo que na Inglaterra chamavam "Antiguidades Populares". Referiase Thoms, aos estudos dos usos e costumes, cerimônias, crenças, romances, refrões, superstições, contos, lendas, mitos, histórias.

A palavra foi criada pela aglutinação dos dois termos anglosaxônicos: Folk no sentido de povo e, lore no sentido de saber, ou seja, "saber tradicional do povo".
A princípio, o conceito de Folclore é visto como a busca de preservar aquilo que estava se perdendo, bem como à concepção de certa espontaneidade do povo. Perspectivas que estavam contextualizadas numa Europa que se industrializava rapidamente.

Entre a Antiguidade e a Idade Média, as manifestações populares, mesmo que provindas de diferentes grupos sociais, não chamavam a atenção pelas diferenças. É, sobretudo, no Renascimento que ocorrerá de fato uma diferenciação entre o que é do povo e o que é da elite. Exemplificando, o balé clássico tornou-se a dança das elites, enquanto outras manifestações foram negligenciadas. Embora, fosse percebida certa interação desses universos, aos poucos, vai se marcando, definitivamente, o que é popular em contraposição ao que é erudito. Apesar do estabelecimento de fronteiras, é interessante notar que os cidadãos eruditos, muitas vezes, identificam-se com o que é do povo, mas muito mais como estudiosos do que participantes, o que, em certa medida só faz aumentar as distâncias entre popular e erudito (OLIVEIRA, 2004). Afinal, é bem comum ver as tradições populares retiradas do seu habitat, analisadas e perscrutadas pelos eruditos e devolvidas às massas em escala industrial. 
O folclore está ligado à vida rural e campestre, algo bem próximo à cultura tradicional (OLIVEIRA, 2004). Enquanto conceito, o folclore abrange o específico e o permanente, o durável. Brandão (1982) adverte para o risco de se definir folclore como a pura sobrevivência intocada, dada a negação de sua condição dinâmica.

"Aquilo que se reproduz entre os pescadores, índios e camponeses como saber, crença ou arte reproduz-se enquanto é vivo, dinâmico e significativo para a vida e a circulação de trocas e de bens, de serviços, de ritos e símbolos entre pessoas e grupos sociais. Enquanto resiste a desaparecer e, preservando uma mesma estrutura básica, a todo momento se modifica. $\mathrm{O}$ que significa que a todo momento se recria" (p.38).

A cultura do folclore é um codificador de identidades, de reprodução dos símbolos que consagram um modo de vida de classe. $\mathrm{O}$ folclore perdura, e aquilo que nele em um momento se recria, em outro precisa ser consagrado. Precisa ser incorporado aos costumes de uma comunidade e ali conservar-se através das gerações. Tradicionalmente, o saber popular que faz o folclore flui através de relações interpessoais.
No caso das danças que constituem folclore de um povo, Sotero e Ferraz (2009) vão distinguilas segundo seus aspectos sagrado e profano. O sagrado faz parte da crença religiosa de um grupo social, estão presentes em cerimônias religiosas e buscam a ligação entre o homem e sua divindade. As danças profanas fazem parte do cotidiano pagão de um grupo social, estão presentes em comemorações. O sagrado e o profano, na opinião de Lara (1998), devem buscar uma relação dialógica na dança. Pois, ambos constituem duas formas de ser no mundo que se opõem e ao mesmo tempo complementam a vida dos indivíduos.

Por conseguinte, uma análise sobre a conceituação da cultura popular nos fez deparar com algo quase que inesgotável. Parece que toda vez que esse tema vem à tona o que se consegue é muito mais confusões que esclarecimentos. Os sentidos atribuídos à cultura popular também sofreram modificações através dos tempos.

Uma definição mais simplista, gerada no senso comum, mostra-nos que popular é tudo aquilo que o povo faz ou fez. Nota-se aqui alguma similaridade com um modo característico de viver e sobreviver. Essa limitação engloba de maneira infinita toda a produção do povo: moda, música, alimentação 
ou algumas outras como colecionar figurinhas, ir ao culto religioso nos fins de semana, reuniões familiares para o almoço de domingo, churrascos com os amigos, enfeitar a casa para as festas natalinas, pendurar roupas no varal, ir pescar, enfim, esta é uma definição que pouco ou nada esclarece.

Pode-se abordar o popular como tudo que o povo consome, ouve, compra ou lê, sem dúvida, uma definição com finalidade comercial. Uma definição reduzida à ideia de alienação e manipulação da cultura do povo. Essa questão pode ser negada por dois motivos. Primeiro, porque essa é uma relação reducionista. Entender que existe uma grande massa de pessoas que consome e aprecia os produtos da indústria cultural, o que os caracteriza como receptores desses produtos, e que a relação da classe popular para com este subproduto é puramente manipulável, seria desprezar qualquer atitude pensada, refletida de seus membros. Trata-se de uma noção de povo como passivo e mero consumidor. Todavia, não se pode deixar de lado o poder manipulador da indústria cultural, negá-lo seria uma atitude ingênua. Seria negar aspectos intrínsecos da relação cultural - a dominação e a subordinação. Se, por um lado, nega-se o poder de inserção cultural, por outro, se afirma um caráter inviolável, puro e intransponível da cultura popular. Estes dois pólos são inaceitáveis, tanto o da autonomia quanto o da incorporação ou domínio total. A questão da manipulação rechaça qualquer possibilidade dos membros da cultura popular perceberem a maneira como são representados e assim concordarem com ela.

A indústria cultural, por sua vez, trabalha e remodela o que quer representar para ajustar as descrições da cultura dominante, bem como definir e divulgar formas de ser dominantes. Eis o perigo pelo qual a difusão cultural passa por estar nas mãos de poucos. A dominação cultural produz efeitos, mesmo que não seja o que se determina, pois é a cultura popular que permite reconhecer-se nas representações ou rejeitá-las, além de fazer leituras que permitam novas construções identitárias. Esse é o ponto do campo de luta pelo significado reivindicado pelos Estudos Culturais. Essa luta acontece nas:

[...] linhas complexas da resistência e da aceitação, da recusa e da capitulação que transformam o campo da cultura em uma espécie de campo de batalha permanente, onde não se obtém vitórias definitivas, mas onde há sempre posições estratégicas a serem conquistadas ou perdidas (HALL, 2003, p. 255). 
Essas questões podem trazer um debate mais intenso sobre as relações culturais, o poder cultural e a implantação cultural. Se as formas de cultura popular comercial são manipulativas é porque, junto com suas prerrogativas e jogos de sedução ou falso apelo, existem elementos de identificação aos quais as pessoas respondem ou atuam conforme são interpeladas pela ideologia vigente. O risco disso é que a tendência é entender as formas culturais como algo inteiro, coerente e puro, ou inteiramente corrompidas ou inteiramente autênticas. Essas formas culturais são ambíguas e contraditórias, principalmente quando se está no âmbito do popular. Por exemplo, podemos colocar a tentativa das escolas em negar a prática de danças como o axé ou funk, porque não é entendida como cultura popular, como algo autêntico, e sim artefato da indústria cultural, algo totalmente corrompido. Contudo, essas manifestações culturais não sobreviveriam se não possuíssem algo de suas origens nas danças e gestos populares, nem iriam tão longe se não contassem com a capacidade de difusão e reconfiguração que a indústria cultural possibilita ao que é popular.

O popular pautado no debate cultural é entendido como categoria de oposição àquilo que é erudito, que pertence às elites. O que é de domínio do povo não pode ser um conteúdo das classes dominantes. Esse pensamento mostra uma possibilidade de compreensão das mudanças das coisas, pois, de tempos em tempos, certas produções populares são elevadas na categoria cultural, ao passo que outras são rebaixadas das classes dominantes para o consumo das massas. Tencionando um maior esclarecimento, podemos citar o uso da calça de brim ou rancheira dos pioneiros estadunidenses à sua atual presença nas passarelas das grifes mais caras; da feijoada da senzala à elevação do preço de seus ingredientes nos mercados; das danças e festas das vilas feudais aos bailes de máscara dos bairros nobres etc. Ou seja, mesmo que o conteúdo dessas práticas sociais seja elevado a outra posição conforme a época, a categoria popular permanece. Ela é compreendida como jogo de forças e relações que mantém a distinção e as diferenças das classes sociais, pouco importando seu objeto, atividade ou qualquer outra coisa.

O que vale é a tensão permanente de relacionamento, influência, oposição e resistência da cultura popular versus a cultura dominante. Para que estas oposições ou trocas aconteçam, é necessário um conjunto de processos institucionais para a sua constituição (HALL, 2003). Nesse sentido, a igreja, a família e a escola - com seu currí- 
culo e disciplinas, como a Educação Física - atuam de modo a definir sua distinção. Quanto à escola, ela atua em consonância com esse processo ao valorizar certos tipos de conhecimentos e negar ou menosprezar outros, dando a idéia de que o popular é estático, congelado. O processo institucional nos dá a idéia de que o popular não se altera. Este fato pode ser facilmente ilustrado com a tradicional concepção transmitida em algumas escolas pela Festa Junina, quando o homem rural é representado como alguém que "fala errado", veste roupas remendadas e possui uma dentição "mal cuidada". A festa junina escolar bem ilustra as diversas formas assumidas pela luta cultural: incorporação, distorção, resistência, negociação e recuperação (HALL, 2003).

Surge, a partir dessas análises, a percepção de uma negociação de símbolos e significados entre o povo e os seus interventores. Por exemplo, referindo-se ao Bumbameu-boi, na ocasião da construção do boibódromo, afirmava-se que tal equipamento significaria o fim desta manifestação cultural. Inversamente, o que se verificou foi a capacidade de negociação entre os folcloristas e a indústria cultural. $\mathrm{O}$ resultado dessas negociações gerou, de um lado, uma reorganização do Bumba-meu-boi passível de se enquadrar nas exigências estéticas da mídia televisiva e, de outro, a conservação e manutenção da tradição expressa na presença dos mitos e lendas desta manifestação.

Com o avanço da tecnologia e da globalização, observa-se a universalização no vestuário, a padronização de alguns hábitos e a ampliação da homogeneização cultural. Neste cenário, as manifestações populares, despontam como um elemento de resistência, uma vez que ao preservar as identidades locais com suas danças, costumes e valores, funcionam também, como resistência a homogeneização por reforçar as especificidades de um local.

Paradoxalmente, o sistema capitalista ressignifica estas manifestações para suas finalidades comerciais. Desta maneira, as práticas culturais populares são transformadas em uma gama de produtos específicos direcionados ao público local. A própria manifestação popular em si, pode se tornar mercadoria ao atrair turistas como é o caso do carnaval carioca.

Cabe ressaltar que, na sociedade capitalista em que vivemos, a valorização e preservação de muitas manifestações culturais ficam atreladas à sua capacidade de conquistar os interesses capitalistas. Como por exemplo, o caso do forró, antes considerada como coisa de nordestino e, hoje, ganha cenário nacional como forró universitário. 
Enfim, qualquer definição do que venha a ser popular articulase ao jogo de força cultural e ao poder de atribuir significado a determinado símbolo e prática social. A idéia de tradição e valorização do que é popular em determinada época não passa de estratégia de poder, algo para fazer valer a afirmação de imutável, inteiro e autêntico.

\section{As danças folclóricas e popu- lares no currículo da Educa- ção Física}

A escola é uma das instituições responsáveis pela socialização do patrimônio cultural, ou seja, responsável pela formação e mediação simbólica que se dá nas interações humanas. "A cultura é o conteúdo substancial da educação, sua fonte e sua justificativa última" (FORQUIM, 1993, p. 14). "Uma teoria cultural da educação, nos dizeres de Silva (2007), vê a educação, a pedagogia e o currículo como campos de luta e conflito simbólicos, como arenas contestadas na busca da imposição de significados e de hegemonia cultural".

A linguagem é um dos aspectos da cultura e, conseqüentemente, a linguagem corporal é um dos aspectos da cultura corporal de movimento, conhecimento a ser tratado pela Educação Física no âmbito es- colar. Para problematizar as temáticas da linguagem corporal como um dos aspectos da cultura corporal de movimento é preciso ter claro que não basta eleger os saberes produzidos pelos diversos grupos sociais, o desafio se apresenta na leitura crítica da realidade, isto é, dos seus contextos ideológicos de produção, manutenção, transformação etc. Exemplificando, ao tematizar a dança no currículo escolar, as atividades didáticas poderão prever situações de estudo e análise histórica da modalidade, as razões de suas transformações, a compreensão do seu significado no contexto social de origem e, finalmente, os alunos poderiam ser convidados a descobrir e sugerir suas próprias formas de dançar, pois, se consideramos o que foi dito anteriormente, a prática formal da dança é produto de outro grupo social, cujos praticantes em pouco ou nada se assemelham ao público escolar.

A linguagem corporal inserida nas danças folclóricas e populares constitui-se como manifestação lúdica, dada sua finalidade comunicativa das emoções, sentimentos e idéias que são extravasadas através dos movimentos carregados de sentido. O ser humano se relaciona com o mundo social, demonstra o que sente e, em razão disso, tem na expressão corporal uma poderosa via de interação. A expressão corporal é, portanto, "a capacidade 
que permite expressar idéias, pensamentos, emoções e estados afetivos com o corpo. Portanto, é uma capacidade de síntese que agrupa todas as outras capacidades no relacionamento com o ambiente" (PÉREZ GALLARDO, 1997, p. 45).

É possível depreender um grande potencial comunicativo na expressão corporal, pois entendemos que ela se encontra no campo da emoção, sua intenção é manifestar sentimentos. No momento em que uma pessoa experimenta as possibilidades do seu corpo, explora formas de ações e gestos, ocorre uma confluência de sentimentos do indivíduo em relação ao grupo e de toda linguagem corporal historicamente e socialmente construída que configura o ser humano, ao mesmo tempo individual e coletivo, porquanto está mergulhada em um caldo cultural profundamente relacionado à sociedade a qual pertence e às linguagens dos diversos grupos que a compõem com suas características peculiares.

Para Neira e Nunes (2006), quando a perspectiva de Educação Física empregada na escola atua com base na linguagem corporal, o que se está a estudar é o gesto sem adjetivá-lo certo ou errado, sem focalizar sua quantidade ou qualidade, sem tencionar a melhoria do rendimento, nem tampouco a manutenção da saúde, da alegria ou do prazer. Nesta abordagem, o gesto fomenta o diálogo por meio da produção cultural, por meio da representação de cada cultura. Se o gesto transmite um significado cultural, o que importa é empreender situações didáticas que ajudem os alunos a lerem e interpretarem a gestualidade que caracteriza as danças folclóricas e populares. $\mathrm{Ou}$ seja, trata-se de ocasiões importantíssimas para compreender as identidades dos diversos grupos que produziram e reproduziram esses artefatos culturais.

As teorias pós-críticas ${ }^{3}$ da educação, ao inspirarem essa concepção curricular de Educação Física nos oferecem os recursos para organizar ações pedagógicas que se proponham a trabalhar a partir das práticas sociais dos grupos que chegam à escola, para pela mediação, socialização e ampliação de saberes, proporcionando-lhes uma melhor compreensão das teias que envolvem os produtos sociais, suas condições e modos de produção, fato este necessário à compreensão da sociedade em que vive para que se possa empreender a desejada transformação social.

3 As teorias pós-críticas da educação ampliaram os marcadores sociais apontados pelas teorias críticas. Segundo Silva (2007), os Estudos Culturais, os Estudos Feministas, o Multiculturalismo, o PósColonialismo, a Teoria Queer e o Pós-Modernismo situam-se no terreno das teorias pós-críticas. 
O currículo da Educação Física inspirado nas teorias pós-críticas tenciona posicionar os educandos como sujeitos da transformação social e contribuir com a construção de uma sociedade mais democrática e justa. Consequentemente, sua prática pedagógica deverá articular-se ao contexto de vida comunitária; apresentar condições para que sejam experimentadas e interpretadas as formas como a cultura corporal é representada no cenário social; ressignificar essas práticas corporais conforme as características do grupo; aprofundar os conhecimentos acerca desse patrimônio e ampliar os saberes dos alunos a respeito da manifestação corporal objeto de estudo. Ensinar Educação Física, então, é um ato dinâmico e permanente de conhecimento centrado na descoberta, análise e transformação da realidade por aqueles que a vivenciam. Com isso, pretende-se não só, a valorização identitária, como também, a ampliação cultural e o reconhecimento das diferenças, promovendo um diálogo cultural que contribuirá para a construção do auto-conceito positivo e respeito com o outro, elementos indispensáveis a uma relação verdadeiramente democrática.

Numa visão de educação que compreende a escola como espaço determinado socialmente para a produção, reconstrução e ampliação cultural, caberá à Educa- ção Física escolar proporcionar aos alunos experiências pedagógicas que viabilizem experiências significativas com as danças presentes no universo cultural próximo e afastado quanto a reflexão crítica acerca das diversas formas de representação cultural veiculadas nessas manifestações, oferecendo a cada aluno a oportunidade de posicionarse enquanto produtor de cultura corporal. Tais preocupações alertam Neira e Nunes (2007), tencionam fazer "falar", por meio do estudo das danças folclóricas e populares, a voz de várias culturas no tempo e no espaço - da família, bairro, cidade, estado, país, a internacional, infantil, juvenil, adulta, sulista, nortista, nordestina, urbana, rural, afro, indígena, imigrante e tantas outras que coabitam o Brasil contemporâneo, além de problematizar as relações de poder explícitas e implícitas.

Para Garcia (1995), ao situar no currículo os conhecimentos que o aluno traz quando entra na escola, o professor o reconhece como sujeito de conhecimento, sujeito capaz, capacidade revelada e reconhecida no já sabido, e capacidade potencial para se apropriar de novos conhecimentos que a escola Ihe pode oferecer.

A articulação da cultura corporal da família e da rua com a cultura da escola, sem hierarquizálas, embora mostrando o que as 
distingue, viabiliza a importância de que todos se reconheçam enquanto sujeitos históricos. Ao processo educativo cabe esclarecer que tanto uma como a outra são parte do que se convencionou chamar de cultura e mais, um professor comprometido, mostrará como os homens e mulheres construíram historicamente sua cultura corporal, que por ser resultado de sua ação, o acesso a ela é direito de todos, e a escola tem que assumir a função de socializála. Pouco a pouco, convém explicar que o conhecimento é parte da luta pelo poder e que é preciso lutar pela garantia de acesso e apropriação, como parte da luta pela democratização da sociedade.

As teorias pós-críticas da educação inspiram a seleção das danças que serão transformadas em objeto de estudo do currículo da Educação Física, mediante os princípios de "justiça curricular", "evitar o daltonismo cultural" e "ancoragem social dos conteúdos".

Tendo em vista a infinidade de danças folclóricas e populares existentes e considerando que cada manifestação corporal veicula os signos de um ou mais grupos culturais, Connell (1993) argumenta favoravelmente à instauração da justiça curricular. A organização do currículo cultural da Educação Física atentará para a distribuição equilibrada de variadas danças. Se a pretensão é valorizar a pluralidade por meio do reconhecimento e estudo do patrimônio cultural corporal, convém eleger as manifestações a partir de uma interpretação cuidadosa do repertório disponível. É fundamental que ao longo do currículo sejam tematizadas danças urbanas e rurais, tradicionais e contemporâneas, analisando o espaço geográfico em que se localizam, ou seja, danças locais, regionais, nacionais e internacionais. Uma atenta seleção seguida de interpretação, aprofundamento e ampliação dos saberes culturais, permitirá o reconhecimento da heterogeneidade social mediante a democratização das identidades e a valorização da diversidade da cultura corporal.

Baseando-se nas idéias de Stoer e Cortesão (1999), outro princípio orientador da seleção das danças folclóricas e populares a serem contempladas pelo currículo da Educação Física consiste em evitar o daltonismo cultural concretizado pelas ações didáticas que promovem a homogeneização ou uniformização da diversidade cultural apresentada pelos alunos, bem como, dos resultados das suas aprendizagens. Muitas vezes, as intervenções pedagógicas buscam amparo em uma noção distorcida de igualdade, tendendo a tratar todos da mesma forma e objetivar, pela ação educativa, o alcance de 
comportamentos idênticos. É o que ocorre quando se reproduzem nas aulas de Educação Física os procedimentos desenvolvidos nas aulas de dança tal qual acontecem nos clubes e academias. Mormente, o resultado é o privilégio atribuído àqueles que dispõem de experiências culturais anteriores vinculadas a experiências rítmicas, o que só faz reforçar certas identidades e minorar outras. O que se pode esperar? A exclusão dos alunos cujas culturas de chegada se distanciam das vivências solicitadas e a marcação negativa de diferenças.

Para evitar o daltonismo cultural, o professor poderá, após uma vivência corporal em íntima consonância com as leituras que os alunos fizeram da manifestação focalizada, promover um debate, visando reconhecer as possíveis diferenças de interpretação dos alunos, estimular a verbalização dos variados pontos de vista, ouvir e discutir os posicionamentos emitidos, apresentar sugestões, oferecer novos conhecimentos oriundos de pesquisas em diversas fontes de informação e recriar a dança abordada com a intenção de posicionar os alunos na condição de sujeitos-autores de produtos da cultura corporal. Os estudantes, após a vivência da manifestação no formato disponível na cultura paralela à escola, podem sugerir transformações, tencionando adequá-la às características do gru- po - quantidade de participantes, diferentes funções assumidas durante a vivência, presença ou não de alunos com necessidades especiais, atenção às diferenças individuais, respeito pelos limites pessoais etc. Uma ação didática não-daltônica reconhece os diferentes repertórios de chegada dos alunos, confronta-os com a temática em tela, modifica a tipologia de relações, amplia os conhecimentos iniciais e produz novos artefatos culturais.

Sob influência das idéias de Grant e Wieczorek (2000), chamamos a atenção para um último princípio curricular, a ancoragem social dos conteúdos. Os autores recomendam uma séria análise sóciohistórica e política das manifestações culturais tematizadas, sempre partindo da sua prática social. O que implica na compreensão e posicionamento crítico com relação ao contexto de produção e reprodução das danças folclóricas e populares. A viabilização desse processo leva em conta tanto as experiências pessoais referentes ao tema em estudo, quanto os conhecimentos veiculados por todas as fontes de informação: meios de comunicação de massa, obras específicas, histórias etc. A condução de atividades de ensino pautadas na ancoragem social, ao tratar respeitosamente todos os discursos possíveis, potencializará o diálogo entre o senso comum, a cultura acadêmica e os 
conhecimentos transmitidos de todas as maneiras. Ajudará os alunos a desvendar os discursos embutidos nas danças que legitimam determinadas experiências e desqualificam outras. Permitirá superar a alienação provocada pela veiculação de informações distorcidas ou fantasiosas, reconhecer e adquirir uma nova visão sobre os saberes corporais disponíveis, sejam eles socialmente valorizados ou marginalizados.

Uma construção curricular baseada nos princípios apontados promoverá um ambiente pedagógico favorável à participação equitativa das múltiplas identidades e a apropriação crítica das danças folclóricas e populares, aspectos fundantes de uma escola comprometida com a construção de uma sociedade mais democrática e menos desigual. Ora, caso não sejam analisadas e compreendidas as relações hierarquizantes que caracterizam as práticas corporais e a forma como são socializadas ou se não houver uma reflexão rigorosa sobre as estratégias empregadas para legitimar certas manifestações e discriminar outras, como será possível construir uma sociedade onde se possa viver melhor?

\section{Considerações finais}

A discussão travada nas páginas anteriores sugere alguns encaminhamentos para a problematização das danças folclóricas e populares no currículo da Educação Física. A argumentação travada, no entanto, foge à lógica dos manuais técnicos de aplicação que, bem comuns na área, simplesmente arrolam atividades a serem instaladas na escola. Inversamente, a proposta aqui apresentada requer a prévia configuração do ambiente institucional para que possa ser levada a cabo. Em primeiro lugar, é necessário, por parte de todos os envolvidos, reconhecer a educação escolarizada como um campo de trabalho pedagógico realizado por professores profissionais do ensino. Isso quer dizer que o compromisso com a reflexão crítica acerca do patrimônio cultural deve ser o eixo das ações docentes, superando o equívoco de estabelecer o grupo de alunos como centro da relação pedagógica e transformando as interações escolares numa relação dialética entre o professor, os alunos, a comunidade e as diversas práticas corporais constituídas como objeto de conhecimento. Um segundo ponto a ser considerado a análise das teias de relações que envolvem as manifestações populares e folclóricas nos mais variados grupos sociais, bem como as implicações destas relações na constituição da vida social.

A partir daí, o desafio dos professores de Educação Física, 
enquanto profissionais do ensino, consiste na elaboração de atividades didáticas que viabilizem a construção do diálogo entre as múltiplas lógicas que atravessam os diferentes grupos que coabitam a sociedade, e que veiculam seus significados por meio da dança. O currículo da Educação Física pautado nas teorias pós-críticas atua com base num conceito dinâmico e histórico da cultura corporal, um processo em contínua construção, desconstrução e reconstrução no jogo das relações sociais de poder, pulverizado na sociedade. Nessa linha de raciocínio, as danças populares e folclóricas ao serem transformadas em temas de estudo do componente, são vistas como artefatos culturais gerados no campo de disputas da cultura mais ampla, o que faz com que carreguem os signos dos grupos culturais que lutam pelo direito a voz e à participação.

Por fim, se o que se pretende é uma ação didática que contribua para a construção de uma sociedade menos justa e desigual, a problematização das danças populares e folclóricas nos currículos de Educação Física não poderá basear-se somente no reconhecimento das diferenças para aceitá-las, o que significaria tratá-las como produtos exóticos oriundos de grupos desqualificados, o que se está sugerindo que é cada dança tenha suas marcas culturais (gestos, ritmos, adereços, representantes, coreografias etc.) transformadas em objeto de leitura crítica, vivência e reflexão. Dessa forma, será possível a organização de situações respeitosas de diálogo cultural, o que proporcionará uma dinâmica de inovação e de enriquecimentos recíprocos.

\section{Referências}

BRANDÃO, C. R. O que é folclore. Brasiliense, 1982.

BRASILEIRO, L. T. O Conhecimento no Currículo Escolar: o conteúdo Dança nas aulas de Educação Física na perspectiva crítica. Dissertação (Mestrado) - Centro de Educação, Universidade Federal de Pernambuco, Pernambuco. 2001. . O conteúdo Dança em aulas de educação física: temos o que ensinar? In: Pensar a Prática, Goiânia, 2006.

CONNELL, R. W. Schools and social justice. Montréal: Our Schools/Our Selves Education Foundation, 1993.

CORAZZA, S. M. Tema gerador: concepção e prática. Ijuí, RS: Editora Unijuí, 2003.

EHRENBERG, M. C. Os currículos de licenciatura em educação física: a dança em questão. 
Tese (Doutorado) - Faculdade de Educação Física -Unicamp, Campinas. 2008.

FORQUIN, J. C. Escola e cultura. Porto Alegre: Artes Médicas, 1993.

FREIRE, P. Conscientização: teoria e prática da libertação - uma introdução ao pensamento de Paulo Freire. São Paulo: Moraes, 1980.

GARCIA, R. L. Currículo e m a n c i p a tór i o e multiculturalismo: reflexões de viagem. In: SILVA, T. T. e MOREIRA, A. F. (orgs.) Territórios contestados: o currículo e os novos mapas políticos e culturais. Petrópolis: Vozes, 1995.

GEERTZ, C. A interpretação das culturas. Rio de Janeiro: Guanabara Koogan, 1989.

GRANT, C. A. e WIECZOREK, $K$. Teacher Education and Knowledge in the "Knowledge Society": the need for social moorings in our multicultural schools, Teachers College Record, v. 102, n.5, 2000. pp. 913 - 935.

HALL, S. A centralidade da cultura: notas sobre as revoluções de nosso temp. Educação \& Realidade. Porto Alegre: p. 15, jul./dez. 1997.

HALL, S. Da diáspora. Identidades e mediações culturais. Belo Horizonte: UFMG Brasília:
Representação da UNESCO no Brasil, 2003.

LARA, L. M. Dança: dimensão sagrada ou profana? In: Conexão: lazer, esporte, educação. Campinas, Faculdade de Educação Física da Universidade Estadual de Campinas, 1998.

LARA, L. M. et. al. Dança e ginástica nas abordagens de educação física escolar. Revista Brasileira de Ciências do Esporte. Campinas, v. 28, n.2, p.155-170, jan. 2007.

MOREIRA, A. F. B. e CANDAU, V. M. Indagações sobre currículo: currículo, conhecimento e cultura. Brasília: MEC/SEB, 2007.

NEIRA, M. G. e NUNES, M. L. F. Pedagogia da cultura corporal: crítica e alternativas. São Paulo: Phorte, 2006.

NEIRA, M. G. e NUNES, M. G. Pedagogia da cultura corporal: motricidade, cultura e linguagem. In: NEIRA, M. G. Ensino de Educação Física. São Paulo: Thomson Learning, 2007. - Educação Física, currículo e cultura. São Paulo: Phorte, 2009.

NELSON, C; TREICHLER, P. A. e GROSSBERG, L. Estudos Culturais: uma introdução. In: SILVA, T. T. (Org.). Alienígenas na sala de aula: uma introdução aos estudos culturais em educação. 
Rio de Janeiro: Vozes, 1995. p. 07-38.

OLIVEIRA, A. J. de. Danças Populares Brasileiras entre a tradição e a tradução: um olhar sobre o grupo urucungos, puitas e quingêngues. Dissertação (Mestrado) -Instituto de Artes, Unicamp, Campinas. 2004.

PÉREZ GALLARDO, J. S. et al. Educação Física: contribuições à formação profissional. ljuí, R.S.: Unijuí, 1997.

SALES, J. R. L. O uso das danças folclóricas no contexto pedagógico da educação física. Dissertação (Mestrado) - Universidade Católica de Brasília. D.F., 2003.

SBORQUIA, S. P. A dança no contexto da educação física: os (des)encontros entre a formação e a atuação profissional. Dissertação (Mestrado)Faculdade de Educação FísicaUnicamp, Campinas. 2002.

. Da formação e atuação profissional do professor de educação física à inovação educativa. Tese (Doutorado) Faculdade de Educação Física Unicamp, Campinas. 2008.

SBORQUIA， S. P.; PÉREZ GALLARDO, J. S. As danças na mídia e as danças na escola. Revista Brasileira de Ciências do
Esporte, Campinas, v.23, n.2, p. 105-118, 2002. . A Dança no Contexto da Educação Física. Ijuí: Ed. Unijuí, 2006

SILVA, T. T. Documentos de identidade: uma introdução às teorias críticas do currículo. Belo Horizonte: Autêntica, 2007.

SOARES C. L. et all. Metodologia do Ensino de Educação Física. São Paulo: Cortez, 1992.

SOTERO, M. A. e FERRAZ, O. L. Uma única dança nunca é uma dança única. Classificação das danças pra uso escolar. In: Anais do XVI Congresso Brasileiro de Ciências do Esporte e III Congresso Internacional de Ciências do Esporte. Salvador, Bahia, 2009.

STOER, S. R. e CORTESÃO, L. Levantando a pedra: da pedagogia inter/multicultural às políticas educativas numa época de transnacionalização. Porto: Afrontamento, 1999.

TORRES SANTOMÉ, J. Globalização e interdisciplinaridade: o currículo integrado. Porto Alegre: Artmed, 1998.

Recebido: 25/fevereiro/2010. Aprovado: 10/abril/2010. 